\title{
DEVELOPMENT OF A COMPREHENSIVE PEDESTRIAN FoOTBRIDGE MANAGEMENT SYSTEM
}

\author{
Claude Munyaneza* and Leopold Mbereyaho \\ Department of Civil, Environmental and Geomatics Engineering, University of Rwanda, College of Science and \\ Technology. P.O Box: 3900 Kigali, Rwanda.
}

\author{
Date received: 29/05/2020, Date accepted: 17/08/2020 \\ *Corresponding author's email: claudemunyaneza6@gmail.com \\ DOI: $10.33736 /$ jcest.2619.2020
}

\begin{abstract}
The footbridges in rural areas have been crucial as the only mean to overcome the rural isolation and allow breaking the cycle of poverty by providing access to such development facilities like education opportunities, markets, medical clinics and other basic services. In Rwanda, under collaboration with Engineers without Borders from German, and International Non-Government Organization Bridge to Prosperity (B2P, some footbridges are already built. In line with the agreement with B2P around 355 bridges are also planned in 5 years. The key challenge is to optimally allocate resources in order to maintain this number of bridges, especially under the current financial constraints. The purpose of this paper was to investigate and propose a pedestrian footbridge management system for Rwanda (PFBMS) which should allow the efficient bridge management, through the analysis of condition data, determination of the ranking and priority of bridge maintenance activities, as well as evaluation of the alternatives of preservation or replacement. The methodology comprises of the use of interview and discussions with district engineers in charge of bridge management, local community using the constructed footbridges as well as bridge builders from B2P. Microsoft Excel analysis tool has been used to developing the deterioration model, and therefore the PFBM was proposed. It is concluded that this system can accurately predict optimal maintenance planning as well as bridge rating.
\end{abstract}

Copyright $\odot 2020$ UNIMAS Publisher. This is an open access article distributed under the Creative Commons Attribution-NonCommercial-ShareAlike 4.0 International License which permits unrestricted use, distribution, and reproduction in any medium, provided the original work is properly cited.

Keywords: Bridge management System, Pedestrian Footbridge, Bridges to prosperity, ranking and prioritization

\subsection{INTRODUCTION}

Proper access to socio-economic facilities and services, such as clinics, schools, and commercial centers, etc. for many people living in rural areas is one of important development priorities for many countries. The development of pedestrian footbridges is one of the most economical and sustainable solutions to rural isolation [1] .

Due to its geographical conditions, Rwanda is committed to address the problem of insufficiency of footbridges in rural areas. Engineers without Borders from German and an International Non-Government Organization Bridge to Prosperity (B2P) that is specialized in the design and construction of pedestrian footbridges have been building pedestrian footbridges in collaboration with districts in Rwanda for the past eight years. The contribution of $\mathrm{B} 2 \mathrm{P}$ resulted into 54 bridges that were built in 19 different districts to serve over 300,000 people, and according to the agreement under action, about 355 bridges more are going to be built in 5 years [2].

One of key objectives for the country would be to optimally allocate resources in order to maintain this number of bridges. This is understandable especially under the current financial environment of limited funds. With the time, those bridges will need to be repaired or strengthened, depending on the severity of their deterioration. Nevertheless, due to financial constraints, especially in developing countries, funds must be divided equally between maintaining the deteriorated bridges and replacement. For this reason, a comprehensive pedestrian footbridge management system is indispensable in order to ensure that fair funds distribution.

The system should not only evaluate the serviceability of bridges, but also provide an optimum maintenance plan considering the limited funds available [3]. 
Some researchers conducted studies about the footbridge construction, evaluation and maintenance. A brief description of the global solution was presented focusing on the construction methods used to ensure a safe working relationship of the structure with its environment [4]. [5] conducted a study on diagnostics and evaluation of footbridges, and using some case studies, they demonstrated the evaluation of bridges after construction should be continuous in order to provide timely necessary status information to allow further action on the concerned. [6] conducted a study on the Degradation of steel footbridges under neglected inspection and maintenance activities and demonstrated that the regular periodic inspection and basic routine maintenance were the only operations to ensure the required lifetime and saving money. Any study about footbridge management system is rarely available or inexistent until today.

This paper presents the development of a pedestrian footbridge management system (PFBMS) for Rwanda. The main purpose of PFBMS is to analyze the footbridge condition data, determine the ranking and priority of bridge maintenance activities, as well as to evaluate the alternatives for bridge preservation or replacement. The methodology consisted of using interviews and discussions with district engineers in charge of bridge management, local community around some constructed bridges as well as bridge builders from bridges B2P. Microsoft Excel analysis tool has been used to developing the deterioration model.

The proposed PFBMS is based on the visual inspection data relating to the targeted footbridge. This to be done firstly by the bridge user (mostly the local communities) who report to the relevant bridge committee. Secondary, the qualified personnel will conduct the routine bridge inspection. Condition State and Discrete Defects are the most types of data collected during the inspection. Condition States are used for future routine maintenance planning by tracking the condition of the bridge components over the long term. Recording of Discrete Defects will help to evaluate the risks related to structural performance. Discrete Defects are also used to continue safe operation of the bridge, as well as the safety of bridge users. In that essence, Condition States are maintenance focused while Discrete Defects are risk-based and consequence driven [7].

\subsection{METHODOLOGY}

\subsection{METHODOLOGY DESCRIPTION}

The main objective of this study is the application and development of pedestrian footbridge management system for Rwanda. As stated above in section 1, the proposed pedestrian Footbridge Management System for Rwanda consists of four models: 1) bridge overall information and database system, 2) priority ranking model, 3) deterioration model, and 4) cost model. The methodology explained below was used to get to this proposal.

An extensive literature search was made, Interviews and discussions were held with district engineers and with Rwanda transportation development agency personnel to acquire all possible information on the status of Pedestrian Footbridge management within country. Discussions were held with Bridge builders at the Bridges to Prosperity organization to obtain feedback on various ideas and to obtain expert advice on the needs and problems at the district level. The inspection Reports conducted by B2P in 2018 were analyzed.

Interviews and Discussion with 68 people including 10 engineers, 8 bridge builders from B2P and 50 local community using constructed footbridges in different districts, were held to understand well and determine how the PFBMS may meet their difficulties for footbridge maintenance. The questions and discussions focused on the current inspection practices and difficulties, management and maintenance operations of pedestrian footbridges, any problem which could advantageously be addressed by a PFBMS, and some recommendations of a scope for the PFBMS which is believed to be appropriate for application at district and national level. 
During this study the key tool used was the Microsoft Excel analysis to conduct the correlation and regression analysis for footbridge defect states and the deterioration factors.

\subsection{MODELS DEVELOPMENT}

The proposed PFBMS for Rwanda consists of four models: 1) bridge overall information and database system, 2) priority ranking model, 3) deterioration model, and 4) cost model. The System should enable the bridge inspectors to use the modern technology of Android app (smart phones) to record data and updating the PFBMS database.

The Virginia Department of Transportation developed a bridge prioritization formula in 2018, which is based on five factors which are importance, condition, design redundancy, structure capacity, and cost effectiveness of a bridge [8]. This formula was here adapted to fit the prioritization factors for pedestrian footbridges in Rwanda.

The developed priority ranking model for this study was based on the bridge prioritization process which consider basic values and concepts of different categories such as bridge condition rating, necessity, risk, type and bridge age. Two different type of bridge treatments were considered for this model, (1) Preservation and Preventive Maintenance (2) Rehabilitation and Replacement.

The deterioration model for the proposed PFBMS was developed based on statistical linear regression. The process involved the use of statistical techniques in the form of correlation analyses and regression analyses, to study and model the deterioration process of pedestrian footbridges in Rwanda. Using the inventory and inspection data of pedestrian footbridges, conducted in 2018 by B2P, an investigation was made into the possible relationships between the bridge condition states as the dependent variable and the bridge deterioration factors as the independent variables. Then statistical analyses were done to fit bridge condition data to linear regression model of deterioration.

\subsection{DEVELOPMENT OF PEDESTRIAN FOOTBRIDGE MANAGEMENT SYSTEM FOR RWANDA}

\subsubsection{DATABASE AND ANALYSIS}

The data of 31 bridges with their condition states inspected in 2018 by B2P were analyzed and used. The data were then imported to Microsoft Excel to conduct the correlation analysis for the bridge condition states versus the deterioration factors. The deterioration modal was then developed with the regression analysis. the independent variables were considered as the deterioration factors whereas the bridge condition state was taken as the dependent variable.

\subsubsection{FOOTBRIDGE REPAIR PRIORITY RANKING MODAL (FBRPRM)}

As a part of the developed PFBMS, a Bridge Repair Priority Ranking Modal (BRPRM) was developed. The bridge prioritization formula developed by the Virginia department of transportation in 2018, was modified to meet the prioritization factors for footbridges in Rwanda. The bridge prioritization process was based on a set of criteria for selecting and ranking a foot bridge as shown on table2. These criteria are based on the basic values and concepts of different categories such as bridge Condition states, Necessity, Risk, Type and bridge Age. This model ranks bridges in two different type of bridge treatments (to be discussed in section 4): (1) Preservation and Preventive Maintenance and (2) Rehabilitation and Replacement. 


\subsubsection{DETERIORATION MODEL}

The Deterioration Model for the proposed PFBMS was developed based on statistical linear regression. The process involved the use of statistical techniques in the form of correlation analyses and regression analyses, to study and model the deterioration process of pedestrian footbridges in Rwanda. Using the inventory and inspection data (conducted in 2018) of pedestrian footbridges by B2P as shown on table 1, an investigation was made into the possible relationships between the bridge condition states as the dependent variable and the bridge deterioration factors as the independent variables. Then Statistical analyses were done to fit bridge condition data to multiple linear regression models of deterioration.

Table 1 Defects states for 30 bridge inspected in 2018 by B2P

\begin{tabular}{|c|c|c|c|c|}
\hline № & Bridge Name & Year built & Age & $\begin{array}{l}\text { Condition } \\
\text { state }\end{array}$ \\
\hline 1 & Muregeya & 2013 & 5 & 90.7 \\
\hline 2 & Taba & 2014 & 4 & 97.6 \\
\hline 3 & Rwamahwa & 2015 & 3 & 98.6 \\
\hline 4 & Gaseke & 2015 & 3 & 99.2 \\
\hline 5 & Mubuga & 2015 & 3 & 99.4 \\
\hline 6 & Shagasha & 2015 & 3 & 98.9 \\
\hline 7 & Nyirakibehe & 2017 & 1 & 99.7 \\
\hline 8 & Gasiza & 2016 & 2 & 99.4 \\
\hline 9 & Budende & 2017 & 1 & 98.6 \\
\hline 10 & Rutaka & 2017 & 1 & 98.4 \\
\hline 11 & Kanyarira & 2016 & 2 & 99.2 \\
\hline 12 & Kumusenyi & 2017 & 1 & 99.2 \\
\hline 13 & Kamasiga & 2012 & 6 & 97.4 \\
\hline 14 & Rugogwe & 2014 & 4 & 99.5 \\
\hline 15 & Rutenderi & 2014 & 4 & 98.7 \\
\hline 16 & Sha & 2015 & 3 & 86.2 \\
\hline 17 & Mariba & 2016 & 2 & 98.2 \\
\hline 18 & Bakokwe & 2013 & 5 & 96.2 \\
\hline 19 & Gasura & 2015 & 3 & 98.7 \\
\hline 20 & Coko & 2016 & 2 & 98.7 \\
\hline 21 & Tubungo & 2016 & 2 & 97.4 \\
\hline 22 & Rugusa & 2017 & 1 & 99.6 \\
\hline 23 & Uwimfizi & 2017 & 1 & 99.3 \\
\hline 24 & Cyumba & 2015 & 3 & 99.0 \\
\hline 25 & Kigohe & 2016 & 2 & 98.3 \\
\hline 26 & Butare & 2016 & 2 & 97.9 \\
\hline 27 & Rwimvubu & 2017 & 1 & 98.3 \\
\hline 28 & Cyamatunda & 2013 & 5 & 96.1 \\
\hline 29 & Kukibuye & 2016 & 2 & 98.8 \\
\hline 30 & Mayange & 2012 & 6 & 74.0 \\
\hline
\end{tabular}

\subsubsection{QUALIFICATION CRITERIA FOR BRIDGE MAINTENANCE, REHABILITATION AND REPLACEMENT}

In the proposed PFBMS model four repair options should be considered for maintaining bridges, (1) Routine Preventive Maintenance (RPM); (2) Condition Related Preventive Maintenance (CRPM); which are applied to each bridge element that need maintenance when it is identified in a bridge inspection 
report. (3) Deck Replacement (DR), (4) Entire foot bridge Replacement (EBR); The entire footbridge replacement includes removing an existing footbridge and constructing a new footbridge.

\subsection{RESULT AND DISCUSSION}

\subsection{RESULTS FROM INTERVIEW AND DISCUSSIONS WITH RESPONDENTS}

Table 2 summarizes the main findings from the Interviews and discussions with different foot bridging personnel:

Table 1 Results from Interview and Discussions

\begin{tabular}{|l|l|l|}
\hline $\begin{array}{l}\text { Question } \\
\text { category }\end{array}$ & Response & $\begin{array}{l}\text { Similarity } \\
\text { Feedback }\end{array}$ \\
\hline 1 & $\begin{array}{l}\text { There is a need of systematic approach for pedestrian footbridge } \\
\text { inspection, data storage and maintenance priority. }\end{array}$ & $88 \%$ \\
\hline 2 & $\begin{array}{l}\text { Most of footbridges in Rwanda are deteriorated due to lack of } \\
\text { preventive maintenance. }\end{array}$ & $94 \%$ \\
\hline 3 & $\begin{array}{l}\text { The district faces the challenge of having many footbridges in the } \\
\text { same relative condition with limited funding sufficient to repair } \\
\text { them, since they were not planned per fiscal year. }\end{array}$ & $55 \%$ \\
\hline 4 & $\begin{array}{l}\text { Although a PFBMS may be difficult to implement, lack of } \\
\text { uniformity in inspection and its procedures suggest a clear need for } \\
\text { a PFBMS and more standard procedures for inspections and setting } \\
\text { maintenance strategies. }\end{array}$ & $60 \%$ \\
\hline 5 & $\begin{array}{l}\text { In addition to the regular inspection, there should be a simple way } \\
\text { to gather some basic information of any footbridge defect that need } \\
\text { an emergency repair. Then, the PFBMS to be adopted should have a } \\
\text { sub model that enable the bridge users (local communities, Bridge } \\
\text { committee, etc) to inform any visible defect using their mobile } \\
\text { phones. }\end{array}$ & $95 \%$ \\
\hline $\begin{array}{l}\text { To be most useful, a footbridge management system for Rwanda } \\
\text { should be implemented at Sector level. This is due to the current } \\
\text { management of footbridges that is under sector's responsibilities. }\end{array}$ & $52 \%$ \\
\hline 6 & $\begin{array}{l}\text { A modern technology like smart phones should be used for } \\
\text { footbridge inspection to facilitate the data recording and data } \\
\text { transference. }\end{array}$ & $70 \%$ \\
\hline
\end{tabular}

\subsection{PEDESTRIAN FOOT BRIDGE REPAIR PRIORITY RANKING MODAL (PFBRPRM)}

The bridge prioritization process was based on a set of criteria for selecting and ranking a foot bridge as shown in Fig. 1. These criteria are based on the basic values and concepts of different categories such as bridge Condition states, Necessity, Risk, Type and bridge Age. This model ranks bridges in two different type of bridge treatments (to be discussed in section 4) The developed priority ranking system for this study is based on two different type of bridge treatments, (1) Preservation and Preventive Maintenance and (2) Rehabilitation and Replacement. 


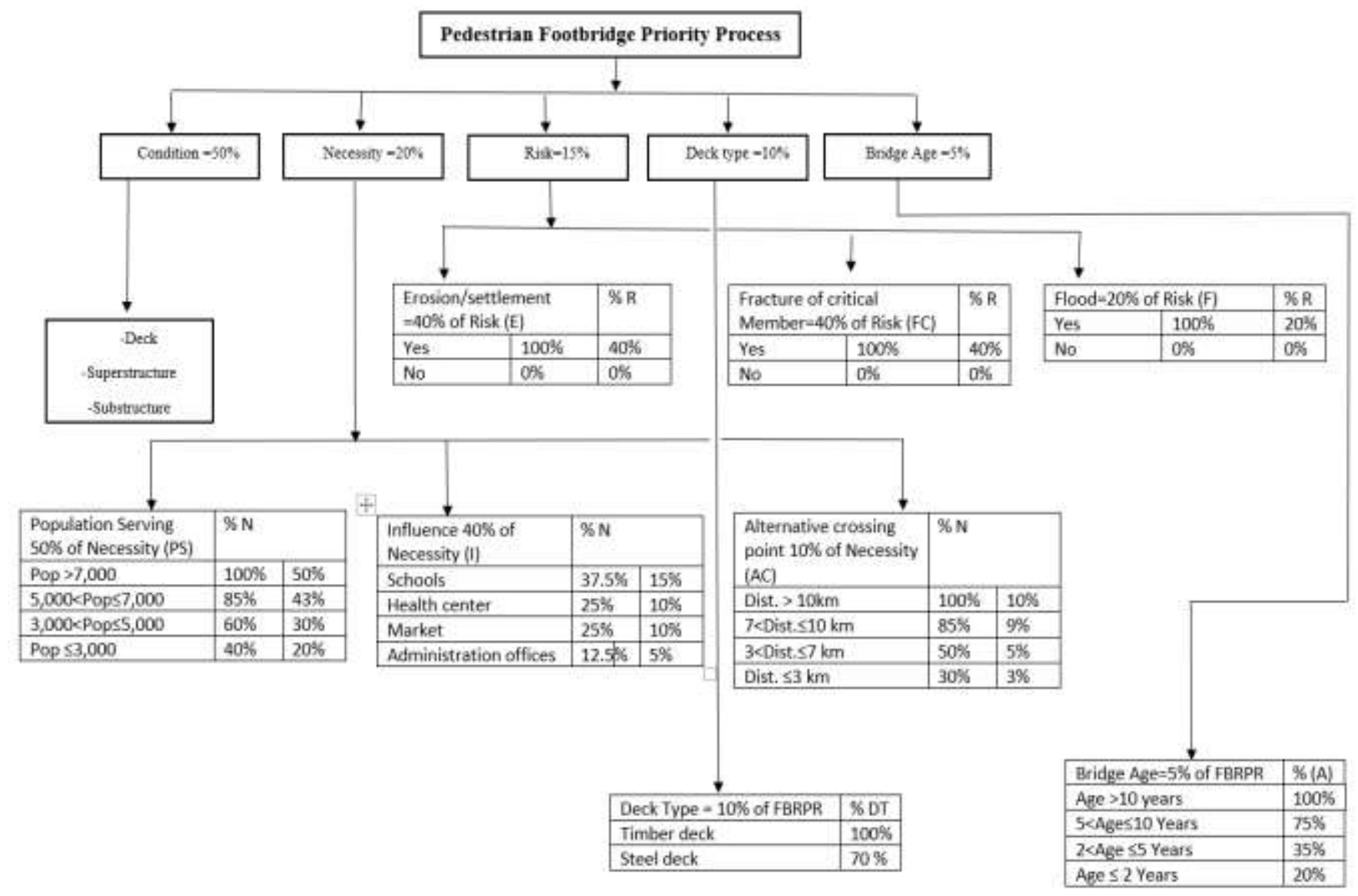

Figure 1 Pedestrian Footbridge Priority Process

\subsubsection{RANKING MODAL FOR REHABILITATION AND REPLACEMENT}

As discussed above in section 2, the bridge prioritization formula developed by the Virginia department of transportation in 2018, was modified to meet the prioritization factors for footbridges in Rwanda. The priority ranking weight for rehabilitation and Replacement is from 0 (least candidate for rehabilitation and replacement) to 100 (most preferred candidate for rehabilitation and replacement).

The formula (1) is used for calculation of the ranking modal:

PRFRR $=\{[v(C S)]+[w(N)]+[x(R)]+[y(D T)]+[z(A)]\}$

Where,

$\mathrm{PRFRR}=$ priority ranking Factor for rehabilitation or replacement (ranging from 0 to 100)

The bridge condition State (CS) can be determined using the formula (2).

$C S($ Bridge condition State $)=(100-$ Bridge condition state $) \frac{v}{100}$

With $\mathrm{v}=50$

The necessity, $\mathrm{N}$ may be calculated using the formula (3)

$\mathrm{N}($ Necessity $)=[(0.5 * P S)+(0.4 * I)+(0.1 * A C)$

PS: Population served by the foot bridge, 
I: Foot bridge Influence (on Schools, markets, health centers, etc.)

AC: Alternative safe crossing point.

The risk, $\mathrm{R}$ is calculated using the following formula (4)

$R($ Risk $)=[(0.4 * E)+(0.4 * F C)+(0.2 * F)$

With:

E: risk for Bank Erosion/Settlement or movement, FC: risk for Fracture of critical member and F: Risk for flood.

DT= Deck Type-Timber deck, Steel Deck, etc.

$\mathrm{A}=$ Foot bridge age which is calculated by subtracting year built from year of inspection.

The coefficient variables $(\mathrm{v}, \mathrm{w}, \mathrm{x}, \mathrm{y}, \mathrm{z})$ are a percentage of each criterion in the rating equation and they are specified by the system user. Table 3 shows the proposed range of category weighting factors.

Table 3 Proposed range of category weighting factors

\begin{tabular}{|l|c|c|}
\hline \multicolumn{1}{|c|}{ Criteria } & Variable Notation & value \\
\hline Condition Rating & $\mathrm{v}$ & $50 \%$ \\
\hline Necessity & $\mathrm{w}$ & $20 \%$ \\
\hline Risk & $\mathrm{x}$ & $15 \%$ \\
\hline Type & $\mathrm{y}$ & $10 \%$ \\
\hline Age & $\mathrm{z}$ & $5 \%$ \\
\hline Total & & $100 \%$ \\
\hline
\end{tabular}

\subsubsection{PRIORITY RANKING MODAL FOR FOOT BRIDGE PRESERVATION}

Two factors were considered for the Priority Ranking System for Foot Bridge Preservation:

1. Foot Bridge Condition State and,

2. Necessity

The ranking Modal can be determined using the following formula (5):

$P R F P=[(0.8 * C S)+(0.2 * N)]$

Where

$\mathrm{PRFP}=$ Priority ranking Factor for preservation ranging from 0 (lowest candidate for preservation) to 100 (highest candidate for preservation).

$\mathrm{CS}=$ Condition State as described by B2P inspection guidelines.

$\mathrm{N}=$ Necessity of foot bridge in the area.

Table 4 shows the values for each factor for Priority ranking Factor for preservation. 
Table 4 Preservation Bridge Prioritizations

\begin{tabular}{|l|l|}
\hline Category & Value \\
\hline Condition State & $80 \%$ \\
\hline Necessity & $20 \%$ \\
\hline Total & $100 \%$ \\
\hline
\end{tabular}

\subsection{DETERIORATION MODELS}

\subsubsection{CORRELATION ANALYSIS OF FOOT BRIDGE CONDITION STATE VERSUS FOOTBRIDGE AGE.}

The correlation analysis has been accomplished between condition states as the dependent variable versus bridge age as the independent variables. The data conditions states were determined from the inspection conducted by B2P in 2018 as shown by table 1 from section 2 .

In cases where a bridge showed inconsistently or contradicting deterioration behavior, the respective bridge was neglected from the development of deterioration model. Looking on Fig.2. 3 bridges (Muregeya, Sha, and Mayange) have been deteriorated inconsistently. So Due to this incredible development in the condition ratings, these bridges were not taken into consideration.

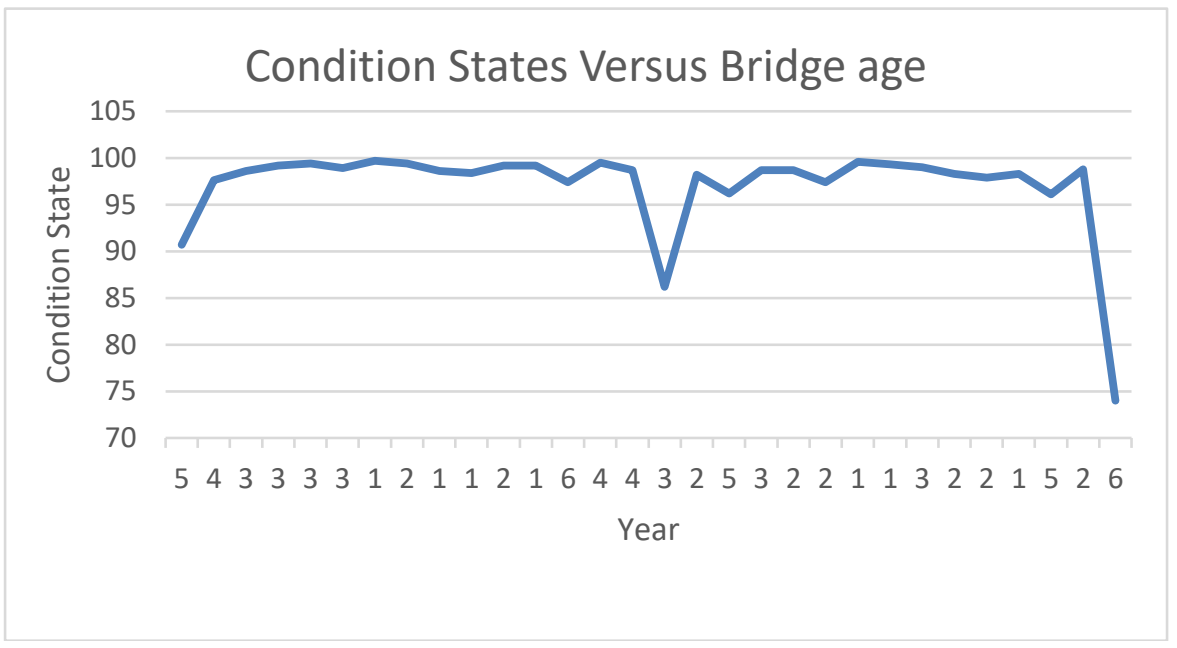

Figure 2 Inconsistent Foot bridge condition states

Table 5 shows the correlation analysis between bridge age and Condition states resulted from Microsoft Excel analysis tool. The bridge age has been calculated by subtracting year built from year of inspection.

Table 5 Correlation Analysis-Condition states vs Bridge Age

\begin{tabular}{|c|c|c|c|c|c|c|c|}
\hline \multirow{2}{*}{$\begin{array}{c}\text { Number } \\
\text { of } \\
\text { Bridge }\end{array}$} & \multicolumn{2}{|c|}{$\begin{array}{c}\text { Condition States } \\
\text { (CS) }\end{array}$} & \multicolumn{4}{|c|}{ Age } & \multirow{2}{*}{$\begin{array}{c}\text { Correlation } \\
\text { Coefficient Cs Vs. } \\
\text { Age }\end{array}$} \\
\cline { 2 - 7 } & Mean & $\begin{array}{c}\text { Std. } \\
\text { dev. }\end{array}$ & Mean & $\begin{array}{c}\text { Std. } \\
\text { Dev. }\end{array}$ & Min. & Max. & $\begin{array}{c}\text { Age } \\
27\end{array}$ \\
\hline 98.5 & 0.94 & 2.55 & 1.39 & 1 & 6 & -0.56 \\
\hline
\end{tabular}




\subsubsection{REGRESSION ANALYSIS}

The regression analysis was conducted between the bridge condition states as the dependent variables and the age as the independent variables. While the Fig.3 displays the relation Age/condition state, the tables 6 to 8 below shows the results. The residual plot has been graphed in order to check that the developed deterioration model is appropriate.

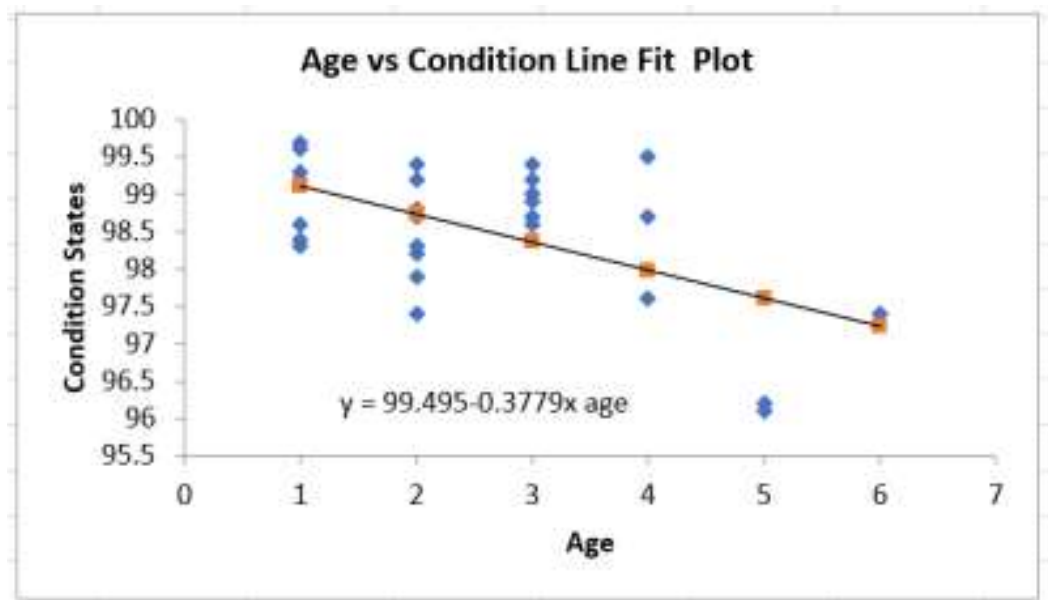

Figure 3 Age Vs Condition line fit plot

Table 6. Model Summary

\begin{tabular}{|l|l|}
\hline MODEL SUMMARY \\
\hline Regression Statistics \\
\hline Multiple R & 0.56306564 \\
\hline R Square & 0.31704292 \\
\hline Adjusted R Square & 0.28972463 \\
\hline Standard Error & 0.7894948 \\
\hline Observations & 27 \\
\hline
\end{tabular}

Table 7. Fitness of Model

\begin{tabular}{|c|c|c|c|c|c|}
\hline ANOVA & & & & & \\
\hline & $d f$ & $S S$ & $M S$ & $F$ & $\begin{array}{c}\text { Significance } \\
F\end{array}$ \\
\hline Regression & 1 & 7.233745127 & 7.233745127 & 11.60552121 & 0.002229362 \\
\hline Residual & 25 & 15.58255117 & 0.623302047 & & \\
\hline Total & 26 & 22.8162963 & & & \\
\hline
\end{tabular}

Table 8. Model Coefficients

\begin{tabular}{|c|c|c|c|c|c|c|}
\hline \multicolumn{2}{|c|}{ Coefficients } & $\begin{array}{c}\text { Standard } \\
\text { Error }\end{array}$ & t Stat & P-value & $\begin{array}{c}\text { Lower } \\
95 \%\end{array}$ & $\begin{array}{c}\text { Upper } \\
95 \%\end{array}$ \\
\hline Intercept & 99.49524 & 0.32160230 & 309.37355 & $2.5670 \mathrm{E}-46$ & 98.8328 & 100.1576 \\
\hline $\begin{array}{c}\text { X } \\
\text { Variable 1 }\end{array}$ & -0.377850 & 0.11091444 & -3.4066877 & 0.00222 & -0.6062 & -0.14941 \\
\hline
\end{tabular}




\subsection{QUALIFICATION CRITERIA FOR BRIDGE MAINTENANCE, REHABILITATION AND REPLACEMENT}

\subsubsection{CONDITION BASED PREVENTIVE MAINTENANCE (CBPM)}

The qualification criteria for CBPM were assumed as:

a. The condition states for footbridge components or elements should be more than 80 .

b. The bridge structure that is older than 1 year excluding some bridges that deteriorate prematurely due serious environmental conditions and/or to poor construction.

\subsubsection{REHABILITATION/ FOOT BRIDGE COMPONENT REPLACEMENT (RFBCR)}

The qualification criteria for RFBCR were assumed as:

a. Superstructure and deck replacement should bring the rehabilitated bridge to acceptable standards. All the components (deck, superstructure, and substructure) of the completed rehabilitated bridge should have a rating of at least 90 or higher.

b. The total cost of rehabilitation should not exceed 70 percent of a new foot bridge cost estimate.

\subsubsection{ENTIRE FOOTBRIDGE REPLACEMENT (EBR)}

The qualification criteria for EBR were assumed as:

a. The condition states for bridge components should be 50 or lower.

b. If the bridge is structurally deficient and the bridge rehabilitation project cost exceeds 70 percent of new bridge costs.

\subsection{DISCUSSION}

\subsection{RESULTS VALIDATION}

The results from interviews and discussion are presented in table1. About $80 \%$ of participants were linked with footbridge management in one way or another. These include the bridge committee are the primary responsible for footbridge inspection and maintenance, bridge builders from B2P and the district engineers who help the community to manage the footbridges.

The Footbridge repair priority ranking model was based on the existing factors for selecting a bridge site to build a footbridge such as social-economic factors, technical factors and accessibility. They were assigned the values based on their impact and how they likely happening to the existing footbridges.

The validation of the developed deterioration model was based on the existing theory of correlation and regression analysis [9]. Looking at table 6, the correlation coefficients for 27 inspected bridges is negative (-056 which indicate that the bridge condition ratings decreased as the bridge ages. Also, the correlation coefficient seems close to -1 , which implies strong negative correlation between Deteriorating states and the bridge age.

Looking at table 5, value for bridge age is much less $(<0.05)$ which indicate that the bridge age is likely to be a meaningful to the model. 
The Fig. 3 shows the flowchart of the proposed PFBMS.

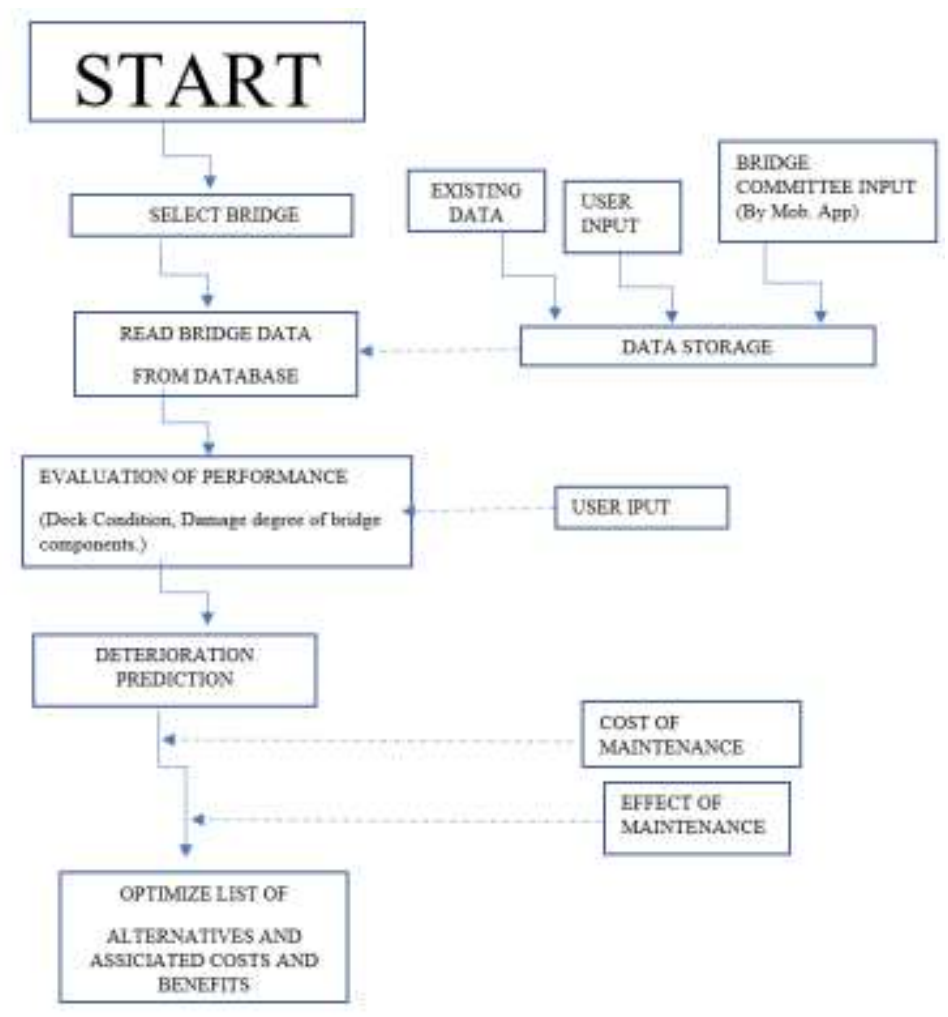

Fig.4 Flow of PFBMS

\subsection{THE USE OF MOB APPLICATION AS PART OF PFBMS DURING BRIDGE INSPECTION.}

Referring to the results of this study, the proposed pedestrian footbridge management system (PFBMS), should be include a mobile application to be used by the inspector in particular the bridge committee who are the main responsible for bridge management and maintenance. The local communities as the main bridge users, provide the information about any bridge defects to the bridge committee. Then in addition to the seasonal inspection done by the bridge committee, the mobile application is used to complete the community inspection data base which is sent and added to the full database in the PFBMS by using community mobile phones.

\subsection{CONCLUSION AND RECOMMENDATIONS}

The purpose of this study was the investigation and development of pedestrian footbridge management system for Rwanda. In the study, the methodology based on the literature review Interviews and discussion with different foot bridging authorities during this research was applied. the following results were therefore achieved:

1. As per majority of participants in this study, A comprehensive PFBMS was needed for Rwanda bridging authorities.

2. The present detailed bridge inspection conducted by Bridges to Prosperity was a suitable starting point for developing a PFBMS and should be from the key database or main module. 
3. The developed PFBMS was adequate and comprehensive enough to support relevant authorities in footbridges management.

Based on the above results, it is recommended that in order to be more efficient, the proposed PFBMS is implemented at sector level. A further study would be welcome for a comparative investigation between different bridge deterioration modals, developed from different analysis such as, Deterministic, Stochastic, Mechanistic, and artificial intelligence. Also, as a part of the proposed PFBMS, the development of a footbridge cost Model is also recommended for further study.

\subsection{ACKNOWLEDGEMENT}

Authors would like to sincerely thank all public and private agencies, as well as experts and other people for provided information and their participation in interview during the study. The leadership of the University of Rwanda, College of Science and Technology is also acknowledged for administrative support provided during this study.

\section{REFERENCES}

[1] A. L. Bang, “Cable Suspended Pedestrian Bridge Design For Rural Construction,” Colorado, 2009.

[2] w. B. t. Prosperity.org, "Government of Rwanda and B2P signed a Memorandum of Understanding to built 355 bridges in 5 years," Kigali, 2019.

[3] Professor, Yamaguchi and S. B.Sc., Kyow, "Development and Practical Application of a Bridge Management System (J-BMS) in Japan," Japan, 2014.

[4] D. s. C. Elsa, A. C. Alvaro and H. Wei-Hua, "Structural Health Monitoring of a Stress-Ribbon Footbridge," 2013.

[5] B. J., H. R., O. J. and V. and J. , "Diagnostics and evaluation of footbridges," 2012.

[6] J. O. Joroslav and H. Richard, "Degradation of Steel Footbridges with neglected and Maintenance," Science Direct, Slovakia , 2016.

[7] B. t. Prosperity, “"Inspection Philosophies and Methods" In Builder Manual,” Colorado-Denver, 2016.

[8] V. D. o. Transportation, "State of Good Repair (SGR) Program Bridge Prioritization Formula," 2018.

[9] D. M. Ahmed, "Correlation and Regression Analysis Tex Book," Ankara-Turkey, 2015.

[10] M. E. Dr. Read and D. T. Paul, "Implementation of a Bridge Management System In The Province of Nova Scotia," Innovation in Bridge Engineering Session of the 2004 Annual Conference of the Transportation Association of Canada, Quebec, 2004.

[11] K. Kawamura, A. Miyamot, D. Frangopol and R. Kimura, ““Performance evaluation of concrete slabs of existing bridges," Engineering Structures, Elsevier Science Direct, 2003. 